\title{
Business Cycle Measurement in the Presence of Structural Change: International Evidence
}

\author{
Hans-Martin Krolzig * \\ Department of Economics and Nuffield College, Oxford University. \\ hans-martin.krolzig@nuf.ox.ac.uk
}

November 11, 2000

\begin{abstract}
By generalizing Hamilton's model of the US business cycle to a three-regime Markov-switching vector autoregressive model, this paper analyzes regime shifts in the stochastic process of economic growth in the US, Japan and Europe over the last four decades. Empirical evidence is established for the presence of a structural break in the expansionary GDP growth for the US and Japan based on an output-employment MS vector equilibrium correction model, and a structural break in the context of a common European business cycle. For the United States the long expansions of recent years signify basic changes in the business cycles pattern. In the case of Japan we identify long episodes of rapid economic expansions (existing until the mid 1970s) and long economic recessions (as in the 1990s). In Europe we find after an episode of catching-up in the 1970s, convergence in the business cycle pattern which suggests the notion of a European business cycle. The multi-regime Markov-switching VARs proposed are profoundly checked for their economic content and statistical congruency, and are found to provide a sound statistical framework for a comprehensive analysis of the business cycle.
\end{abstract}

JEL Classification: E32, F43, F47, C32.

Keywords: Business cycles; Regime shifts, Markov switching; Structural change; Employment; Impulse-response analysis; Cointegration; European Union; Time series analysis.

\section{Introduction}

Recent theoretical and empirical business cycle research has revived interest in the co-movement of macroeconomic time series and the regime-switching nature of macroeconomic activity. For the statistical measurement of macroeconomic fluctuations, the Markov-switching autoregressive time series model has become increasingly popular since Hamilton's (1989) application of this technique to measure the US business cycle. There has been a number of subsequent extensions and refinements.

In this paper we use the approach innovated by Hamilton in his analysis of the US business cycle to analyzes regime shifts in the stochastic process of economic growth in the United States, Japan and Europe over the last four decades. These economies have been subject to structural change manifested in form of structural breaks, i.e. permanent large shifts in the long-run mean growth rate of the economies, and persistent changes in the volatility of the growth process. The study of these phenomena,

${ }^{*}$ Financial support from the UK Economic and Social Research Council under the grant L138251009 is gratefully acknowledged. All the computations reported in this paper were carried with the MSVAR class for Ox: see Krolzig (1998). Helpful comments were received from two anonymous referees, as well as seminar audiences at the 'Growth and Business Cycles in Theory and Practice' conference in Manchester, 2000. Address of the author: Hans-Martin Krolzig, University of Oxford, Department of Economics, Manor Road, Oxford OX1 3UL, UK. 
which are distinctively different from a reoccurring cycle of expansions and recessions constituting the business cycle, requires to allow for more than two-regimes. In order to represent the non-linear, regimeswitching, and the common factor structures of the business cycle simultaneously, this paper will also consider multivariate extensions of Hamilton's original model. By generalizing the Markov-switching model to a multi-regime, possibly integrated-cointegrated multiple time series model, empirical evidence can be established for the presence of common nonlinear business cycles and structural change. The significance drawn from the empirical evidence leads to a critique of traditional separation of the assessment of the business cycle and economic growth.

The paper proceeds as follows: Section 1 introduces the multi-regime Markov-switching multiple time series model as a useful tool for the statistical assessment of the business cycle. In section 2 this model is applied to US output and employment data. The case of Japan is considered in section 3: We identify long episodes of rapid economic expansions (existing until the mid 1970s) and long economic recessions (as in the 1990s). The investigation of the European business cycle presented in section 4 finds convergence in the business cycle pattern of six EU countries which suggests the notion of a European business cycle. The episode of catching-up in the 1970s requires a third regime. Finally section 5 concludes.

\section{Methodology}

The general idea behind regime-switching models of the business cycle is that the parameters of a time series model of some macroeconomic variables depend upon a stochastic, unobservable regime variable $s_{t} \in\{1, \ldots, M\}$ which represents the state of business cycle. In the original contribution of Hamilton (1989), contractions and expansions are modeled as switching regimes of the stochastic process generating the growth rate of real output $\Delta y_{t}$ :

$$
\Delta y_{t}-\mu\left(s_{t}\right)=\alpha_{1}\left(\Delta y_{t-1}-\mu\left(s_{t-1}\right)\right)+\ldots+\alpha_{4}\left(\Delta y_{t-4}-\mu\left(s_{t-4}\right)\right)+u_{t} .
$$

In (1) the regimes are associated with different conditional distributions of the growth rate of real output, where the mean growth rate $\mu$ depends on the state or 'regime', $s_{t}$. For a meaningful business cycle model, $\mu_{1}$ should be negative in the first regime ('recession') and positive in the second regime ('expansion'), $\mu_{2}>0$. The variance of the disturbance term, $u_{t} \sim \operatorname{NID}\left(0, \sigma^{2}\right)$, is assumed to be the same in both regimes.

The stochastic process generating the unobservable regimes is an ergodic Markov chain defined by the transition probabilities:

$$
p_{i j}=\operatorname{Pr}\left(s_{t+1}=j \mid s_{t}=i\right), \quad \sum_{j=1}^{M} p_{i j}=1 \quad \forall i, j \in\{1, \ldots, M\} .
$$

Maximum likelihood (ML) estimation of the model can be based on a version of the ExpectationMaximization (EM) algorithm discussed in Hamilton (1990) and Krolzig (1997b). By inferring the probabilities of the unobserved regimes conditional on an available information set, it is then possible to reconstruct the regimes.

It is important to note that, by definition, univariate Markov-switching models as proposed by Hamilton (1989) are only able to capture some of the stylized facts of the business cycle. They can capture the non-linearity or asymmetry stressed in some part of the literature but, obviously, they are unable to reflect the idea of comovement among time economic series. Our methodology for assessing the business cycle is based on the generalization of Hamilton's model to a Markov-switching vector 
autoregressive model characterizing business cycles as common regime shifts in the stochastic process of some macroeconomic time series. Modeling a vector of time series does not only correspond to the definition of the business cycle, but does also improve the inferences of the Markov process to extract the common 'business cycle' component from the group of economic time series if the business cycle is a common feature of theses variables.

Our point of departure is a Markov-switching vector equilibrium-correction (MS-VECM) model (see Krolzig, 1997b for an overview). Suppose that the $k$-th dimensional time series vector $y_{t}$ is integrated of order one, $y_{t} \sim I(1)$, such that $\Delta y_{t}$ is stationary. Then the

$$
\Delta y_{t}=\sum_{i=1}^{p-1} \Gamma_{i} \Delta y_{t-i}+\Pi y_{t-p}+v\left(s_{t}\right)+u_{t}
$$

where $u_{t} \mid s_{t} \sim \operatorname{NID}\left(\mathbf{0}, \Sigma\left(s_{t}\right)\right)$ and $\Pi=\alpha \beta^{\prime}$ with $\alpha$ and $\beta$ being $k \times r$ full rank matrices. If there are $r$ linearly independent vectors $\beta_{j}, j=1, \ldots, r$ such that $\beta_{j}^{\prime} y_{t}$ is stationary, then $y_{t}$ is called cointegrated of rank $r$. As in the Hamilton model (1) the regimes are generated by a hidden Markov chain (2).

By generating dynamic factor structures, this research strategy provides a synthesis of the dynamic factor and the non-linear approach to the modeling of macroeconomic fluctuations. Diebold and Rudebusch (1996) considered these two approaches as the most important contributions to business cycle research in the last twenty years.

\section{The US Business Cycle}

A serious problem associated with the Hamilton model (1) of US GNP growth is that for more recent samples (i.e. beyond 1984) Boldin (1996) and Clements and Krolzig (1998) found that an adequate description of the US business cycle (in the sense of generating regime durations consonant with estimates based on the NBER chronology, for example) requires the introduction of a third regime and a regime-dependent error variance. In the following we reconsider the three-regime model of post-war US employment and output data proposed by Krolzig and Toro (1998). The model is a cointegrated vector autoregressive Markov-switching process, where some parameters are changing according to the phase of the business and employment cycle. Employment and output are found to have a common cyclical component, and the long run dynamics are characterized by a proportional cointegrating vector between employment and output, with a time trend included as a proxy for technological progress and capital accumulation.

Suppose, the long-run relationship between (the logs of) output, $y_{t}$, and employment, $n_{t}$, is given by the cointegration vector $\beta^{\prime}=(1:-1)$ and the regime-dependent deviation from the trend in per-capita output $\mu\left(s_{t}\right)=\mathrm{E}\left[y_{t-1}-n_{t-1}-\gamma t\right]$. Then each regime $m$ is associated with a particular attractor $\left(\mu_{m}, \delta_{m}^{*}\right)$ given by the equilibrium growth rate $\delta_{m}^{*}$ and the equilibrium mean $\mu_{m}$ :

$$
\left[\begin{array}{cc}
\Gamma_{11}(\mathrm{~L}) & \Gamma_{12}(\mathrm{~L}) \\
\Gamma_{21}(\mathrm{~L}) & \Gamma_{22}(\mathrm{~L})
\end{array}\right]\left[\begin{array}{c}
\Delta y_{t}-\delta^{*}\left(s_{t}\right) \\
\Delta n_{t}-\delta^{*}\left(s_{t}\right)
\end{array}\right]=\left[\begin{array}{l}
\alpha_{1} \\
\alpha_{2}
\end{array}\right]\left(y_{t-1}-n_{t-1}-\mu\left(s_{t}\right)-\gamma t\right)+\left[\begin{array}{l}
u_{1 t} \\
u_{2 t}
\end{array}\right] .
$$

Thus the regime-dependent drift term $\delta^{*}\left(s_{t}\right)$ is the equilibrium growth rate, and shifts in the $\delta^{*}\left(s_{t}\right)$ map out changes in the business cycle state (e.g., expansion, contraction). The equilibrium mean $\mu\left(s_{t}\right)$ gives the state-dependent equilibrium level of labor productivity: shifts in $\mu\left(s_{t}\right)$ reflect changes in equilibrium per-capita output. This bivariate system could be easily extended to higher dimensional macroeconomic growth models introducing physical and human capital accumulation, population growth, unemployment etc. For the simplicity of exposition we shall focus on the two-dimensional case. 
We start to show that US data ${ }^{1}$ from 1960 to 1997 strongly support the cointegration hypothesis made in (4). Short-run and long-run dynamics can be jointly estimated in the Markov-switching vector equilibrium-correction model (3) with three regimes representing recession, growth and high growth. Krolzig (1996) discusses how the cointegration properties of the MS-VECM can be analyzed with a vector autoregression (VAR) of finite order. The analysis is based on the VARMA representation of MSVAR models. Using the properties of this representation, a two stage maximum likelihood procedure can then be applied: the first stage involves approximating the VARMA with a finite-order VAR model and applying Johansen's maximum likelihood procedure (see Johansen, 1995). The results for a VAR(4) are given in table 1 . The tests support the presence of exactly one cointegrating vector. The homogeneity restriction is accepted with $\chi^{2}(1)=0.6077$ at a marginal significance level of 0.4356 . Thus the long-run equilibrium is given by $y_{t}-n_{t}-\gamma t=\mu$. In other words, per-capita output is found to be trend-stationary.

Table 1 Johansen Cointegration Likelihood Ratio Test.

\begin{tabular}{crrrrrrr}
\hline \hline & \multicolumn{3}{c}{ Maximal Eigenvalue Test } & \multicolumn{3}{c}{ Trace Test } \\
\hline $\mathrm{H}_{0}$ :rank $=r$ & $\mu$ & $-T \log (1-\mu)$ & $T-k^{2} p-1$ & $95 \%$ & $-\mathrm{T} \sum \log ()$. & $T-k^{2} p-1$ & $95 \%$ \\
\hline$r=0$ & 0.1346 & $20.39^{*}$ & $19.23^{*}$ & 19.0 & $32.32^{* *}$ & $30.48^{*}$ & 25.3 \\
$r \leq 1$ & 0.0811 & 11.93 & 11.25 & 12.3 & 11.93 & 11.25 & 12.3 \\
\hline \hline
\end{tabular}

** Significant at $1 \%$ level, * Significant at $5 \%$ level.

On the second stage, conditional on the estimated cointegrated matrix, the remaining parameters of the MS-VECM process can be estimated using the EM algorithm for MS-VARs. As in Krolzig and Toro (1998), the empirical model was parameterized as a three-regime first-order MS-VECM:

$$
\left[\begin{array}{cc}
1 & -\Gamma_{12} L \\
0 & 1-\Gamma_{22} L
\end{array}\right]\left[\begin{array}{c}
\Delta y_{t} \\
\Delta n_{t}
\end{array}\right]=\nu\left(s_{t}\right)+\left[\begin{array}{c}
\alpha_{1} \\
\alpha_{2}
\end{array}\right]\left(y_{t-1}-n_{t-1}-\gamma t\right)+\left[\begin{array}{l}
u_{1 t} \\
u_{2 t}
\end{array}\right] .
$$

As the three-regime first-order MS-VECM process 5 is subject to regime shifts in the (I)ntercept and regime-dependent (H)eteroskedasticity, we denote it $\operatorname{MSIH}(3)-\operatorname{VECM}(1)$. The estimated parameters of the model using data from 1960 (3) to 1997 (1) are presented in table 2. $\Delta y_{t-1}$ was found to be insignificant in both equations and therefore dropped. A likelihood test of the regime-invariance of the error variance clearly rejected the null hypothesis, $\chi^{2}(6)=42.605$ [0.0000]. A comparison of the log-likelihood, the Akaike information criterion (AIC) and the Hannah-Quinn criterion (HQ) for the MS-VECM and its linear counterpart (in brackets) supports the significance of the regime shifts.

Note that the adjustment parameter $\alpha_{2}$ in the employment equation is highly significant while the adjustment parameter $\alpha_{1}$ in the output equation is insignificant. This allows to interpret output as the stochastic trend while employment partially adjusts towards the equilibrium. Altogether, the MS-VECM confirms the importance of the vector equilibrium correction mechanism for the data set under consideration.

The intercept term in equation (5) can be decomposed into in the regime-dependent drift term $\delta^{*}\left(s_{t}\right)$, the state-dependent mean growth rate of output and employment (adjusted for the secular increase in labor-productivity), and the regime-dependent equilibrium mean $\mu\left(s_{t}\right)$. From the identity

$$
\nu\left(s_{t}\right)=\Gamma \delta\left(s_{t}\right)-\alpha \mu\left(s_{t}\right)
$$

where $\Gamma=\mathrm{I}_{2}-\Gamma_{1}=\left[\begin{array}{cc}1 & -\Gamma_{12} \\ 0 & 1-\Gamma_{22}\end{array}\right]$ and $\delta\left(s_{t}\right)=\left[\begin{array}{l}\delta^{*}\left(s_{t}\right) \\ \delta^{*}\left(s_{t}\right)\end{array}\right]$, we can deduce:

$$
\mu\left(s_{t}\right)=\left(\alpha^{\prime} \alpha\right)^{-1} \alpha^{\prime}\left(\Gamma \beta_{\perp}\left(\alpha_{\perp}^{\prime} \Gamma \beta_{\perp}\right)^{-1} \alpha_{\perp}^{\prime}-\mathrm{I}_{2}\right) \nu\left(s_{t}\right),
$$

\footnotetext{
${ }^{1}$ The data used in this study are drawn from the OECD database.
} 
Table 2 The US and Japanese Business Cycle, 1960 (3) - 1997 (1).

\begin{tabular}{|c|c|c|c|c|}
\hline & \multicolumn{2}{|c|}{ US: MS-VECM } & \multicolumn{2}{|c|}{ Japan: MS-DVAR } \\
\hline & $\Delta y_{t}$ & $\Delta n_{t}$ & $\Delta y_{t}$ & $\Delta n_{t}$ \\
\hline \multicolumn{5}{|c|}{ Regime-dependent intercepts } \\
\hline \multirow[t]{2}{*}{$\nu_{1}$} & -0.0024 & -0.0013 & 0.0023 & 0.00006 \\
\hline & 0.0022 & 0.0009 & 0.0024 & 0.0009 \\
\hline \multirow[t]{2}{*}{$\nu_{2}$} & 0.0066 & 0.0025 & 0.0098 & 0.0041 \\
\hline & 0.0010 & 0.0005 & 0.0009 & 0.0004 \\
\hline \multirow[t]{2}{*}{$\nu_{3}$} & 0.0147 & 0.0057 & 0.0228 & 0.0043 \\
\hline & 0.0018 & 0.0007 & 0.0016 & 0.0009 \\
\hline \multicolumn{5}{|c|}{ Short-run dynamics } \\
\hline \multirow[t]{2}{*}{$\Delta n_{t-1}$} & 0.1346 & 0.5176 & 0.0537 & -0.2974 \\
\hline & 0.1367 & 0.0583 & 0.1673 & 0.0784 \\
\hline \multicolumn{5}{|c|}{ Equilibrium correction } \\
\hline \multirow[t]{2}{*}{$\alpha$} & -0.0456 & 0.0325 & & \\
\hline & 0.0335 & 0.0122 & & \\
\hline \multicolumn{5}{|c|}{ Regime 1: Variance $\times(10)^{-4}$} \\
\hline$\Delta y$ & 1.0632 & 0.3309 & 1.0410 & 0.0645 \\
\hline$\Delta n$ & 0.7519 & 0.1821 & 0.1758 & 0.1292 \\
\hline \multicolumn{5}{|c|}{ Regime 2: Variance $\times(10)^{-4}$} \\
\hline$\Delta y$ & 0.1559 & 0.0020 & 0.3756 & -0.0170 \\
\hline$\Delta n$ & 0.3428 & 0.0022 & -0.1007 & 0.0758 \\
\hline \multicolumn{5}{|c|}{ Regime 2: Variance $\times(10)^{-4}$} \\
\hline$\Delta y$ & 0.0600 & 0.0094 & 1.0924 & 0.2086 \\
\hline$\Delta n$ & 0.4981 & 0.0059 & 0.3415 & 0.3414 \\
\hline LogLik & 1213.84 & $(1175.00)$ & 1103.56 & $(1042.17)$ \\
\hline AIC & -16.1747 & $(-15.8639)$ & -14.7015 & $(-14.0839)$ \\
\hline HQ & -15.9680 & $(-15.7895)$ & -14.5114 & $(-14.0260)$ \\
\hline \multirow[t]{2}{*}{$\mathrm{SC}$} & -15.6661 & $(-15.6808)$ & -14.2336 & $(-13.9415)$ \\
\hline & Erg.Prob & Duration & Erg.Prob & Duration \\
\hline Regime 1 & 0.1966 & 5.986 & 0.1621 & 11.492 \\
\hline Regime 2 & 0.5073 & 7.973 & 0.8377 & 59.394 \\
\hline Regime 3 & 0.2961 & 5.150 & 0.0002 & 52.900 \\
\hline
\end{tabular}

Note: The italized numbers represent the standard errors of the estimated coefficients and the regime-dependent correlations of the error terms.

where $\beta_{\perp}$ and $\alpha_{\perp}$ are the orthogonal complements of $\alpha$ and $\beta$.

Using the ML estimates reported in table 2, we get the following estimates for the equilibrium mean of (detrended) labor productivity, $\mu\left(s_{t}\right)=\mu_{s_{t}}$, over the three phases of the business cycle:

$$
\left[\mu_{1}, \mu_{2}, \mu_{3}\right]=\left[\begin{array}{lll}
-0.0011 & 0.0203 & 0.0436
\end{array}\right],
$$

and the corresponding estimates of the mean growth rate $\delta^{*}\left(s_{t}\right)=\delta_{s t}^{*}$ of the economy in recessions, expansions and high-growth recoveries:

$$
\left[\delta_{1}^{*}, \delta_{2}^{*}, \delta_{3}^{*}\right]=\left[\begin{array}{lll}
-0.0028 & 0.0065 & 0.0147
\end{array}\right] .
$$

Thus the different phases of the business cycle are not only associated with shifts in the underlying growth rate of the economy, but also with shifts in the gross measurement of labor productivity. This implies that observing the cyclical movements in labor productivity helps to sharpen the detection of business cycle turning points. 

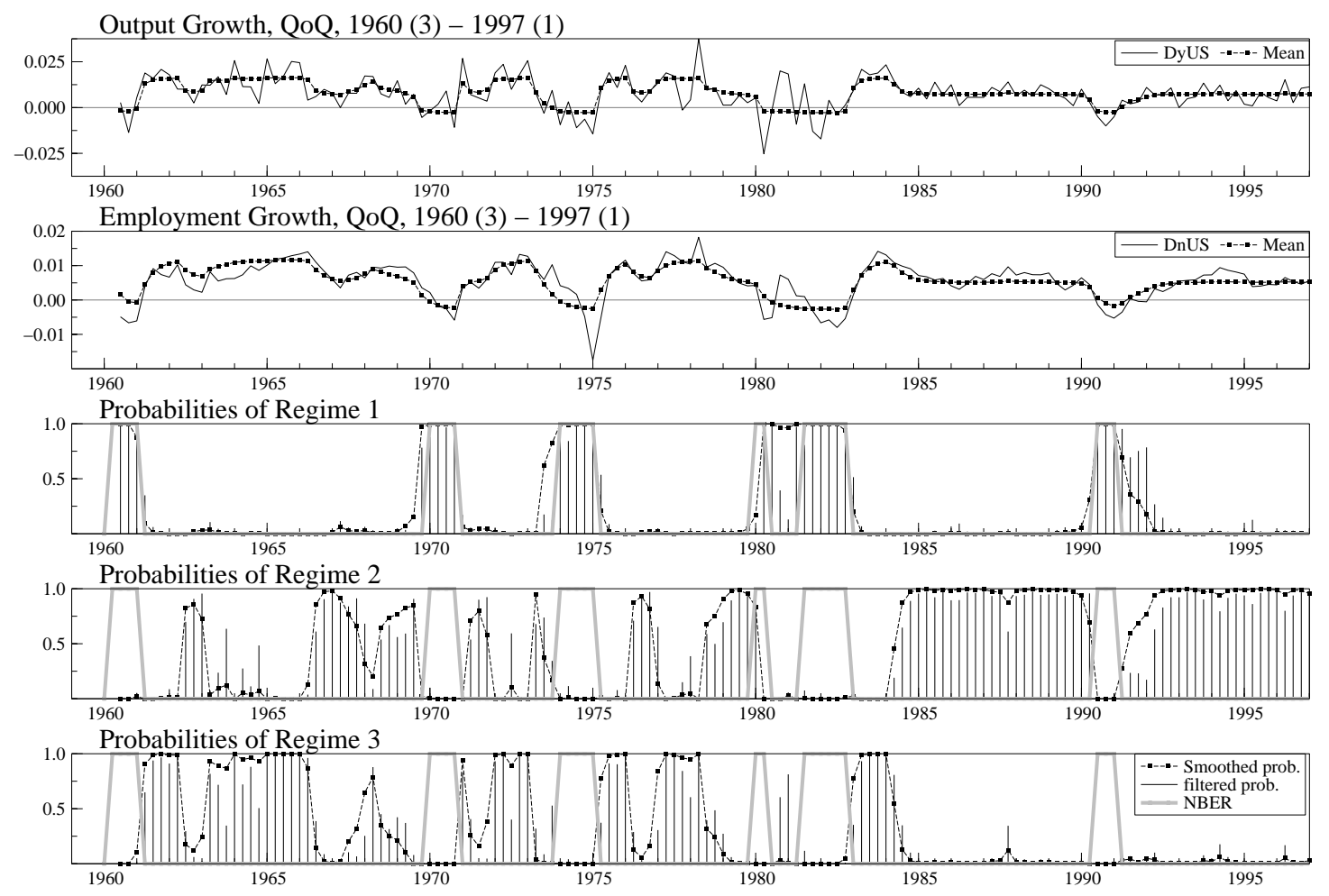

Figure 1 The US Business Cycle.

The transition matrix is given by

$$
\mathbf{P}=\left[\begin{array}{lll}
0.8330 & 0.0644 & 0.0005 \\
0.0320 & 0.8746 & 0.1936 \\
0.1350 & 0.0610 & 0.8058
\end{array}\right]
$$

Note that the $i j-$ th element is $p_{i j}=\operatorname{Pr}\left(s_{t}=i \mid s_{t-1}=j\right)$. The regimes are persistent with a duration of recessions of one and a half year.

The resulting regime probabilities are plotted in the lower three panels of figure 1. The filtered regime probabilities are shown with a dashed line and the smooth probabilities are shown with a bold line. The filtered probability can be understood as an optimal inference on the state variable (whether the system is in a boom or recession) at time $t$ using only the information up to time $t$, i.e. $\operatorname{Pr}\left(s_{t}=m \mid Y_{t}\right)$, where $m$ stands for a given regime. The smoothed probability stands for the optimal inference on the regime at time $t$ using the full sample information, $\operatorname{Pr}\left(s_{t}=m \mid Y_{T}\right)$. The findings confirm the conventional wisdom of a business cycle which can be separated in three stages: recession, growth, and high growth. It can be seen that regime 1 depicts very precisely the recessions of 1970, 1973/74, 1979/80 and 1990. Regime 2 represents normal growth episodes; while regime 3 characterizes highgrowth episodes mainly occurring after recessions. The upper two panels show how the inferred regime probabilities are translated into shifts in the mean growth rate of output and employment: Thus the bold line represents the contribution of the hidden Markov chain to the fluctuations in the variables of the system.

Note that regime 3 is observed until 1985 only, which might indicate a structural change in the phase structure of the business cycle. Expansions after 1985 (regime 2) are characterized by a lower mean growth rate and reduced volatility of macroeconomic fluctuations. This structural break in the 

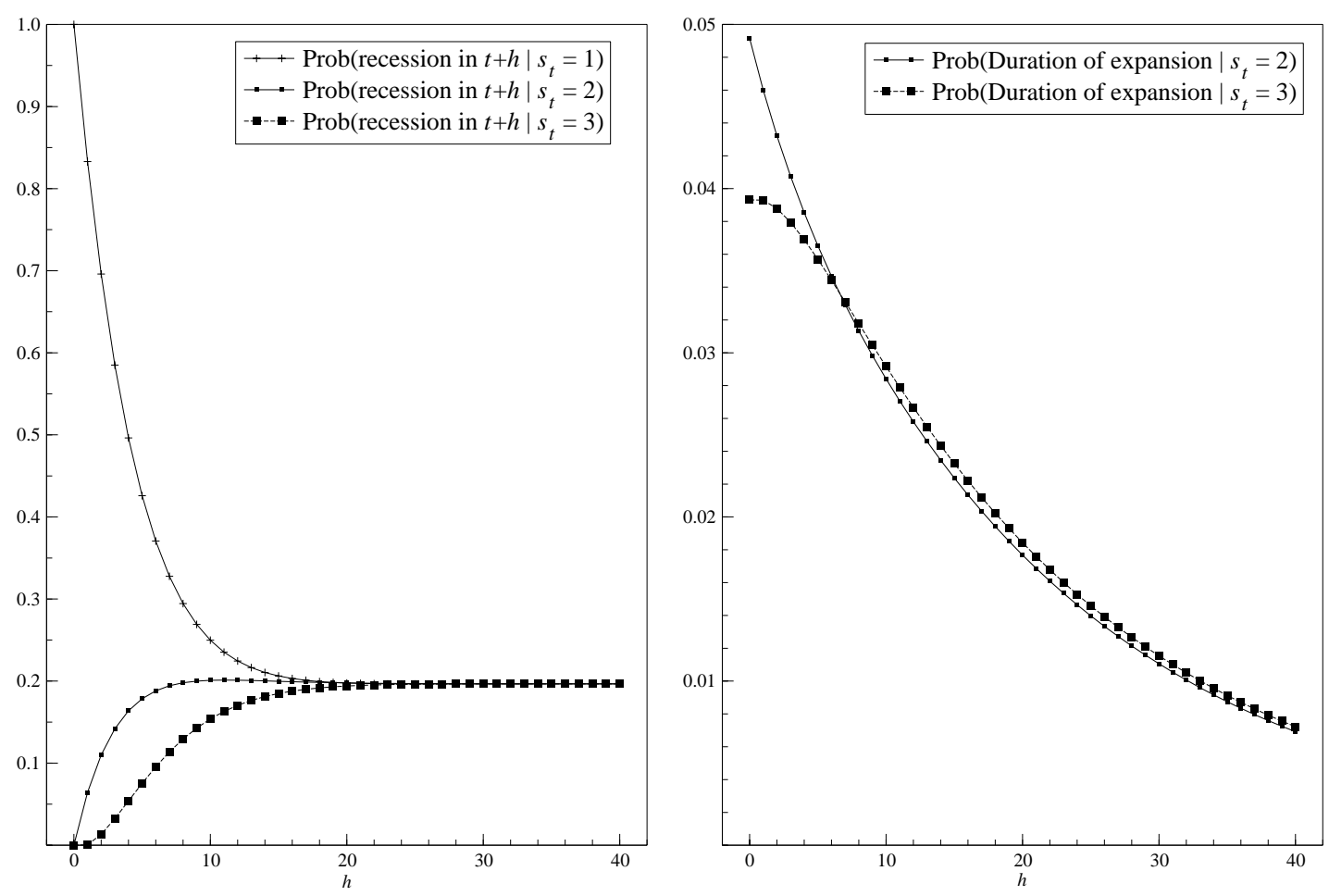

Figure 2 The Duration of an Expansion and the Probability of a Future Recession.

volatility of US output growth coincides with the findings of McConnell and Quiros (1998). They found a substantial reduction in the volatility of durable goods production beginning with the first quarter of 1984, which appears to be correlated with a decline in the share of durable goods accounted for by inventories.

Two types of economic recoveries from recessions can be found for the US in the 1960-1997 period (see figure 1). The first type leading from a recession into high growth (transition from regime 1 to 3) describes the aftermath of the recessions in 1960, 1970, 1973/74 and 1980-82. The second type of recovery is characterized by normal economic growth after a recession (transition regime 1 to 2 ) and was observed after the 1990/91 recession. The implied probabilities for the duration of the economic expansion is illustrated in figure 2 which also presents the probability of a recession in $t+h$ when being in regime $s$ at time $t$. A 'recession into high growth' transition is followed by a slightly longer expansion period than a 'recession into normal growth' transition. The mean duration of expansions is 20.56 quarters in the former case and 21.34 quarters is the later.

To signify the basic changes in the business cycles pattern, we will now discuss the implications of these findings for the properties of recoveries from a recession. For doing so we employ the methodology proposed in Krolzig and Toro (1998) which takes into account the shock and the history of the system as in Koop, Pesaran and Potter (1996). The history is represented by the given state from which we shock the system whereas the nature of the shock is given by the specific state to which we move. One of the advantages of this methodology is that non-Gaussian innovations (say, a change in the phase of the cycle) might be what some economists have in mind when they refer to 'cyclical shocks'; that is, investigating the dynamics of some variables in the transition from boom to bust. This reflects the idea introduced by Krolzig (1997b) that if the unobservable variable is to be interpreted as the state of the business cycle, an impulse response analysis should look at cyclical fluctuations in terms of the response 

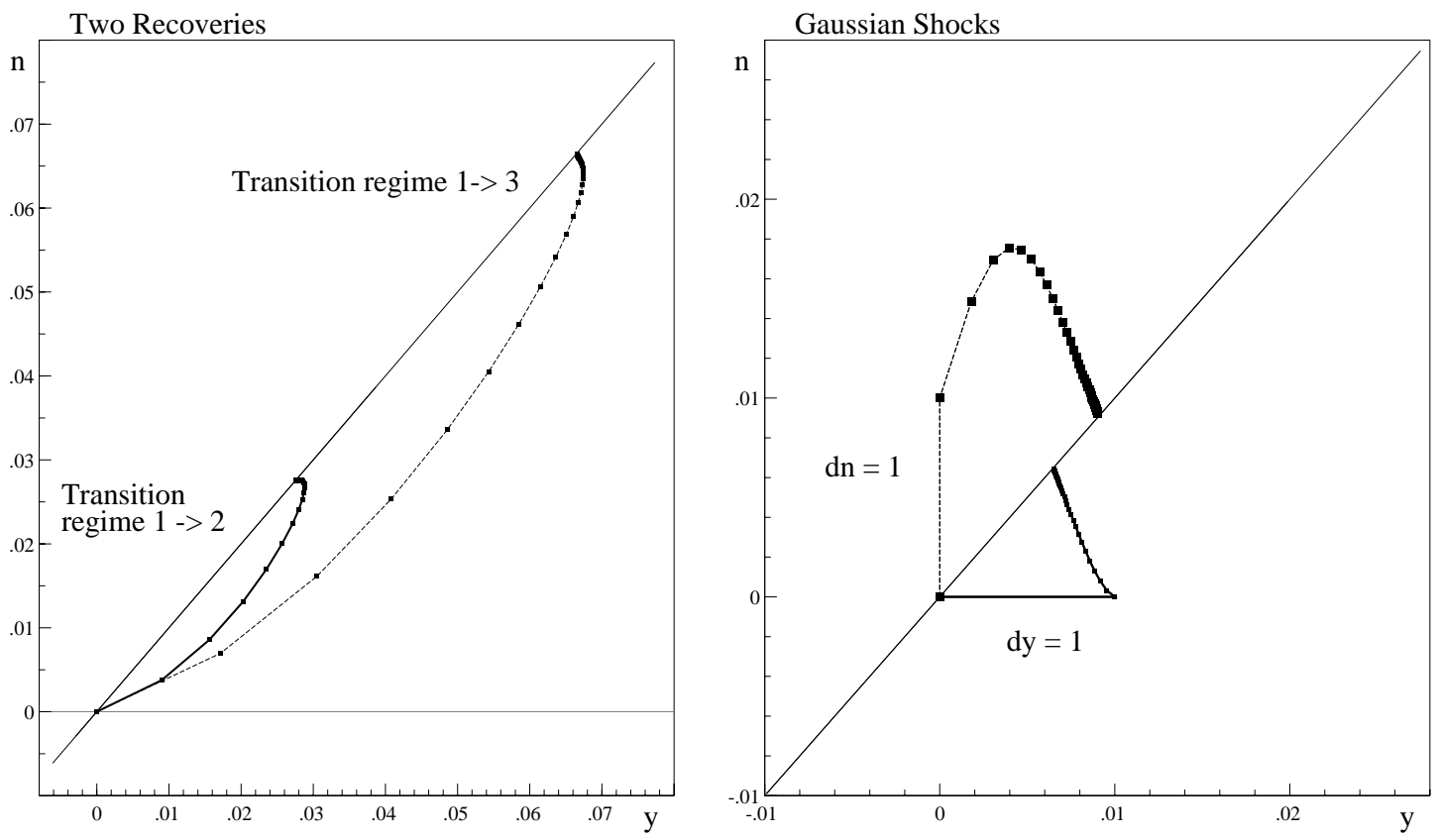

Figure 3 Impulse response analysis.

of the variables to changes in the regime of the state variable.

In figure 3, the impulse responses have been graphed in the employment-output space in order to illustrate the dynamics that played an important role in the US economy for the period of our analysis. The graph on the LHS shows (i) the strong job creation in case of recovery from a recession (regime 1) via the 'high-growth' regime 3, and (ii) the restrained growth in case of a recovery via the "normalgrowth' regime 2. The impulse-responses are measured as changes in the conditional expectation of the observable variables of the system $x_{t+h}=\left(y_{t+h}, n_{t+h}\right)^{\prime}$ at time $t+h$ given a transition in the state of the regime variable $s_{t}$ at time $t: \mathrm{E}\left[x_{t+h} \mid s_{t}=3\right]-\mathrm{E}\left[x_{t+h} \mid s_{t}=1\right]$ and $\mathrm{E}\left[x_{t+h} \mid s_{t}=2\right]-$ $\mathrm{E}\left[x_{t+h} \mid s_{t}=1\right]$. The dynamic effect of regime shifts are due to (i) changes of the current state and hence to the conditional expectation of future regime (as illustrated in figure 2) and (ii) the autoregressive transmission of intercept shifts. In order to get more insights, we compare these effects on the RHS to the response of output and employment to a one percentage innovation in each of the variables. As the autoregressive coefficients and the adjustment parameters are time-invariant, the responses with regard to Gaussian shocks are regime-invariant.

We conclude that the three-regime Markov-switching VECM is a congruent representation of the US business cycle in output and employment. In order to back this evidence further we explore model alternatives with two, three and four regimes, respectively. Testing for the number of regimes is a difficult enterprise in the Markov-switching context. Conventional testing approaches are not applicable due to the presence of unidentified nuisance parameters under the null of linearity. For example, under the hypothesis of regime-invariant intercepts $\nu_{1}=\nu_{2}=\nu_{3}$ and regime-invariant variances $\Sigma_{1}=\Sigma_{2}=\Sigma_{3}$, the transition probabilities $p_{i j}$ are unidentified. The scores associated with parameters of interest under the alternative may be identically zero under the null. Formal tests of the Markov-switching model against linear alternatives employing the standardized LR test designed to deliver (asymptotically) valid 
inference have been proposed by Hansen (1992, 1996), Garcia (1998), but are computationally demanding and therefore infeasible for vector systems. Furthermore it delivers only a bound on the asymptotic distribution of the standardized LR test. The test is conservative, tending to be under-sized in practice and of low power. In our case, economics can help.

It might be worth noting that the structure of the MS-VECM is designed to reflect reoccurring, persistent deviations from a linear DGP. That does not automatically imply that the regime shifts are associated with business cycle transitions. To achieve an ex-post identification of the MS-VECM as a business cycle model we compare the dating of the US business cycle to classical business cycle datings. In figure 1 we overimposed business cycle datings issues by the NBER to the graph of the regime probabilities. Using the smoothed regime probabilities, the coverage of NBER recessions is 0.9977 and the 0.9207. Thus the MSIH(3)-VECM(1) does not miss any recession. The uncertainty regarding the detection of economic expansions is only a bit higher. The average probability of misjudging an expansion (regime 2 and 3 ) is less than $8 \%$. Altogether, the business cycle measured by the empirical MS-VECM is highly synchronized with the US business cycle as dated by the NBER.

Table 3 Markov-switching and NBER business cycle classification.

\begin{tabular}{cccccc}
\hline \hline MS Model & $M$ & Synchronization & $\operatorname{Pr}\left(s_{1}=1 \mid\right.$ recession $)$ & $\operatorname{Pr}\left(s_{1}=1 \mid\right.$ expansion $)$ & AIC \\
\hline \multirow{3}{*}{ MSIH-VECM } & 2 & 0.5656 & 0.9722 & 0.5098 & -16.1419 \\
& 3 & 0.9259 & 0.9543 & 0.0793 & -16.1747 \\
& 4 & 0.9616 & 0.9602 & 0.0381 & -16.1091 \\
\hline \multirow{3}{*}{ MSI-VECM } & 2 & 0.9565 & 0.8982 & 0.0327 & -15.9751 \\
& 3 & 0.9654 & 0.9066 & 0.0236 & -16.0107 \\
& 4 & 0.8938 & 0.3605 & 0.0073 & -16.0062 \\
\hline \multirow{3}{*}{ MSIH-DVAR } & 2 & 0.5801 & 0.9657 & 0.4915 & -16.0612 \\
& 3 & 0.9556 & 0.9159 & 0.0370 & -16.1157 \\
& 4 & 0.9576 & 0.9528 & 0.0415 & -16.0282 \\
\hline \multirow{3}{*}{ MSI-DVAR } & 2 & 0.9537 & 0.8893 & 0.0343 & -15.8616 \\
& 3 & 0.9637 & 0.8880 & 0.0222 & -15.9075 \\
& 4 & 0.9161 & 0.5077 & 0.0082 & -15.8722 \\
\hline \hline
\end{tabular}

Notes: MS-DVAR denotes a Markov switching model in differences, resulting for $\alpha=0$ in equation 5. The MSIH denoted a Markov switching process with regime shifts in the (I)ntercept and regime-dependent (H)eteroskedasticity. An MSI-VAR is the same MS-VAR process but with an regime-invariant variancecovariance matrix. 'Synchronization' reports the probability that the NBER dated cycle and the Markov chain are in the same state of recession or expansion. ' $\operatorname{Pr}\left(s_{1}=1 \mid\right.$ NBER recession) ' denotes the synchronization of MS and NBER recessions. It is measured as the average smoothed probability of beeing in regime 1 of the estimated MS-model when the US economy is in a recession according to the NBER. Similarily ' $\operatorname{Pr}\left(s_{1}=1 \mid\right.$ NBER expansion) ' reports the probability of a recession infered from the MS-VAR when the US economy is in state of an expansion according to the NBER.

In table 3 the compare the synchronization of the model proposed with alternative models having two, three or four regimes. The MSI(2)-VECM(1) is able to generate turning points consistent with the NBER dating, but the residuals of the model are heteroskedastic. The model is misspecified. In general it is found that including the deviation of labor productivity from its trend improves the detection of business cycle turning points as well as the fitting. Allowing for regime-dependent variances confronts the MLE procedure with the problem to account for regime-shifts in the conditional first and the second moment of the process. The result is a very pure capturing of NBER recessions when two-regime models are considered. Adding a fourth regime to the model, improves but these models have a rich parameterization and pure fitting relatively to their number of parameters.

In the next section we apply the model (4) to Japanese output and employment data to analyze the ability of the model to detect regime shifts in the stochastic process of other countries than the US. 

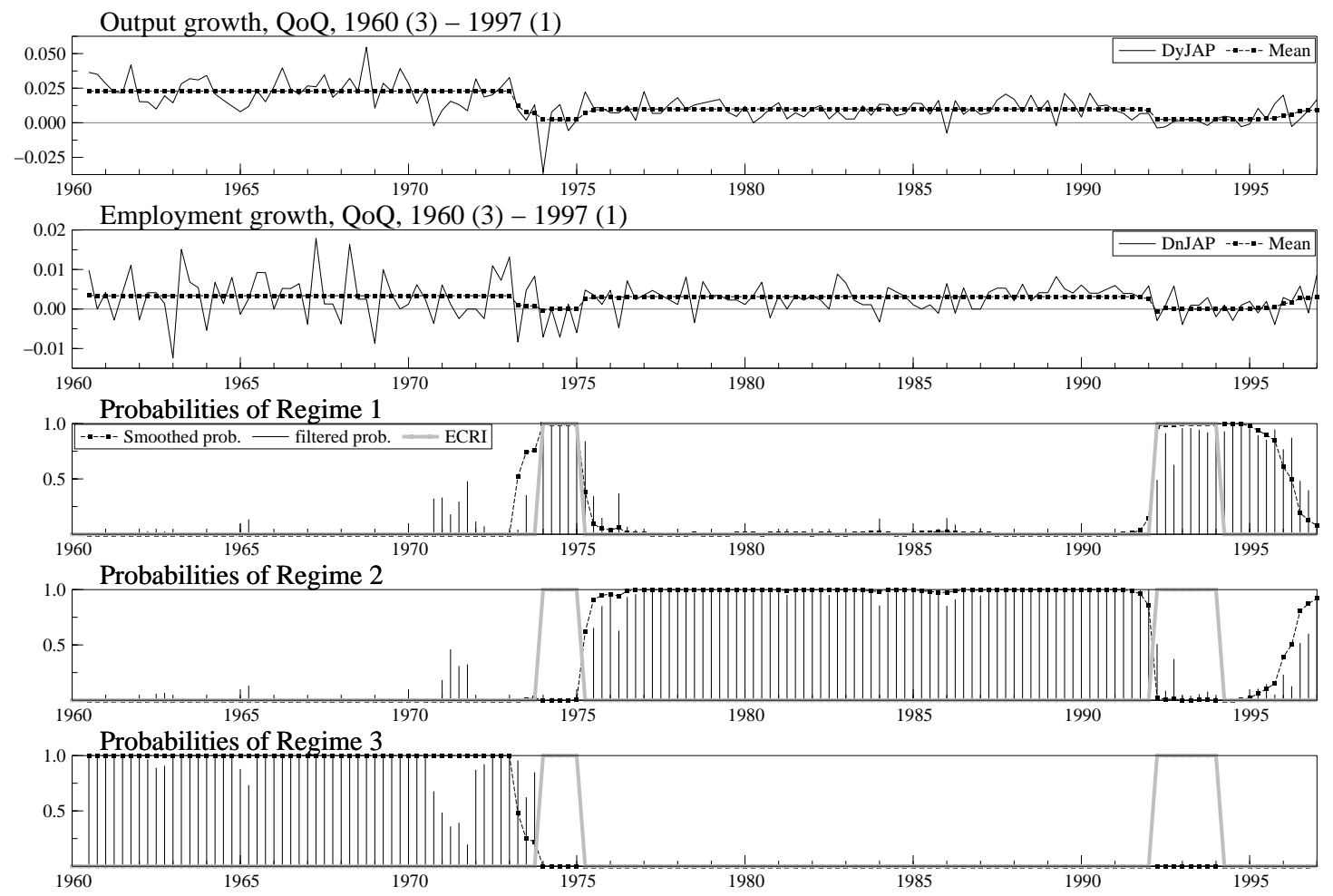

Figure 4 The Japanese Business Cycle.

\section{The Japanese Business Cycle}

One of the stylized facts of the Japanese postwar economic history is the extremely high economic growth in the pre-1974 era: Japan's economy expanded rapidly from the mid-1950s through the 1960s. The annual growth rate averaged close to $11 \%$ in real terms for the decade of the 1960s. And it was well above twice Japan's average prewar growth rate of about $4 \%$ a year. It is generally agreed that the rapid expansion of Japan's economy since the late 1950s was powered by an immense capital accumulation. This high expansion rate of economic activity was connected with major fluctuations. But except for short growth recessions in 1961/62, 1965 and 1970/71, the Japanese economy enjoyed double-digit real economic growth rates during the 1960s and early 1970s. This ended with the first oil crisis in 1973/74. With a sharp contraction in macroeconomic activity and inflation rising to more than $20 \%$ in 1974 , the country found itself in the first recession it had experienced since the early postwar years. The recession was followed by a slowdown in the trend rate of economic growth in the following decades: Economic activity recovered somewhat but never reached the levels of the rapid growth-period. After the collapse of the Japanese stock market, the country entered an ongoing recessionary phase in 1992.

Analyzing Japanese output and employment data from 1960 (3) to 1997 (1) reveals a striking difference of the Japanese economy to the US: the non-stationarity of trend-adjusted labor productivity over the last four decades. As output and employment are not cointegrated, the equilibrium adjustment term in (4) is dropped. For this reason, we are left with a MS-VAR model in differences, denoted MS-DVAR.

The estimated parameters of the MS-DVAR model are presented in table 2. The transition matrix is 
given by

$$
\mathbf{P}=\left[\begin{array}{ccc}
0.9130 & 0.0168 & 0.0189 \\
0.0870 & 0.9832 & 3 \times(10)^{-13} \\
2.5 \times(10)^{-5} & 2.1 \times(10)^{-10} & 0.9811
\end{array}\right]
$$

As some of the $p_{i j}$ went to zero, the ML estimation procedure converged to a corner solution. The Markov chain is essentially non-ergodic as the process does not return to the third regime. This allows to interpret the third regime as a historic event which does not reoccur in the post-1973 period (see figure 4). While the third regime reflects the structural break in 1973 (4), the regimes 1 and 2 of the Markov chain reflect reoccurring expansion and contraction episodes. Hence, our analysis of the Japanese business cycle nests the business cycle model of Hamilton (1989) and non-recurring Markovswitching models used for the determination of change points (see, inter alia, Chib, 1998). Having identified the break point, the model then works like an ergodic two-regime hidden Markov chain model with dummies for the break in 1973 (4) affecting the intercept and the variance of the process.

Table 4 Markov-switching and ECRI business cycle classification.

\begin{tabular}{cccccc}
\hline \hline MS Model & $M$ & Synchronization & $\operatorname{Pr}\left(s_{1}=1 \mid\right.$ recession $)$ & $\operatorname{Pr}\left(s_{1}=1 \mid\right.$ expansion $)$ & AIC \\
\hline \multirow{3}{*}{ MSIH-DVAR } & 2 & 0.4341 & 1.0000 & 0.6208 & -14.4583 \\
& 3 & 0.9040 & 0.9596 & 0.1014 & -14.4069 \\
& 4 & 0.9128 & 0.3809 & 0.0356 & -14.3869 \\
\hline \multirow{3}{*}{ MSI-DVAR } & 2 & 0.4300 & 0.6237 & 0.5888 & -14.6829 \\
& 3 & 0.9232 & 0.9957 & 0.0838 & -14.7015 \\
& 4 & 0.9456 & 0.3846 & 0.0000 & -14.7265 \\
\hline \hline
\end{tabular}

As in case of the US business cycle model, the regime classification of the MS-VAR is close to traditional business cycle datings. In figure 4 the contraction periods issued by the Economic Cycle Research Institute (ECRI) are overimposed to the smoothed and filtered probabilities of the MS-VAR. Using the ex-post (smoothed) regime probabilities, the coverage of Japanese recessions is 0.9986 and the coverage of expansions is 0.9197 . We conclude that the MSIH(3)-DVAR(1) model is a valid statistical representation of the Japanese business cycle and that the detection of business cycle turning points is very precise. The business cycle synchronization and model fitting statistics reported in table 4 also support an MSI(3)-DVAR(1) model. But this model is not congruent as a likelihood test of the regimeinvariance of the error variance clearly rejects the null hypothesis, $\chi^{2}(6)=55.304[0.0000]$.

A comparison of the regimes of the US and Japanese Business Cycle is performed in figure 5: The LHS graphs compare the effects of a recession. The Japanese recessions are much more pronounced: they take longer and the losses of output and employment are much more pronounced. The RHS graphs show the different interpretation of the third high-growth regime in the US and Japan. In the US model, the third regime picks up strong balanced growth of output and employment for up to 20 quarters. In contrast the third regime of the Japanese model represents pre-1973 expansions characterized by very strong and long-lasting growth of output and average labor productivity. As compared to the second regime reflecting post-1973 expansions, the difference with regard to employment is negligible.

These findings demonstrate the flexibility of the MS-VAR approach in modeling business cycles as different as the one in the US and Japan over the last four decades. It is worth noting that due to the regime shifts in the long-term mean rate of economic growth, Hamilton's two-regime model of the US business cycle fails (not shown). In contrast, it is possible to establish well-defined empirical evidence by generalizing the Hamilton model:

(1) By identifying turning points of the business cycle as imminent occurring regime shifts in the 

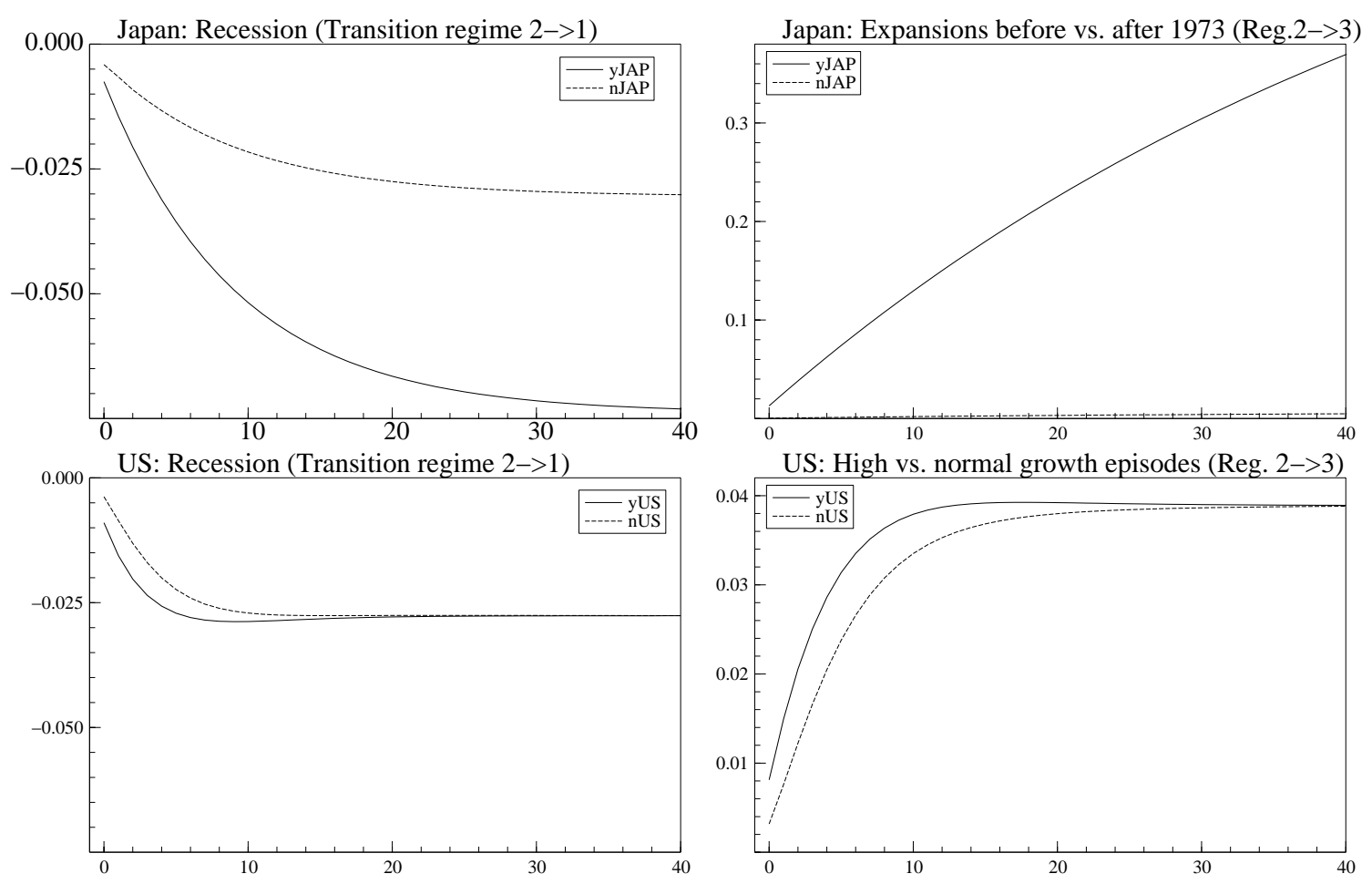

Figure 5 Comparison of the Regimes of the US and Japanese Business Cycle.

mean growth rate of the Japanese economy, we have found clear empirical evidence for the asymmetry of the Japanese business cycle.

(2) There is clear evidence for a structural break in the trend of the Japanese economy by the end of 1973.

(3) In addition to the regime shifts in the mean growth rate, we have shown that the post-1973 period is characterized by a less volatile growth pattern.

These conclusions are consistent with much of available theoretical and empirical evidence. In the following analysis of the European business cycle we will look for a common cycle among the GDP growth of six EU member countries. It is worth noting that this idea could be applied to sectorial or regional data of the countries considered so far (see Krolzig and Sensier, 2000, for the application of a three-regime MS-VECM to disaggregated UK industrial production data).

\section{The European Business Cycle}

Despite the importance of the transmission of shocks across countries, various concepts of common features and the recent appreciation of empirical business cycle research, there has been little attempt to investigate international business cycles with modern non-linear time series models. Still, most studies consider business cycle phenomena for individual countries only. First attempts at the analysis of international business cycles with Markov-switching models have been undertaken by Phillips (1991), Filardo and Gordon (1994) and Krolzig (1997a). Phillips's study of a two-country two-regime models was the very first multivariate Markov-switching analysis of all. Filardo and Gordon (1994) have extended his analysis to a trivariate two-regime model by using leading indicators for the prediction of 
turning points. In this paper we follow the approach proposed in Krolzig (1997a), stressing the importance of a data-driven model specification which enables us to derive new and economically meaningful results. Important issues that arise in the analysis of the European Business Cycle are: (i) the convergence process of Southern Europe and (ii) the secular decline of the mean growth rates of most OECD countries in the post-Bretton Woods era (see also Artis, Krolzig and Toro, 1999). Two-regime models representing contractions and expansions are inconsistent with these two stylized facts of the postwar economic history of Western Europe.

For these reasons we again consider a three-regime Markov-switching vector autoregression with regime-dependent covariances. Since a cointegration analysis gave no clear indication of the presence of cointegrating vector, the variables are modeled in first differences:

$$
\Delta y_{t}=\nu\left(s_{t}\right)+\Gamma_{1} \Delta y_{t-1}+u_{t}, \quad u_{t} \mid s_{t} \sim \operatorname{NID}\left(\mathbf{0}, \Sigma\left(s_{t}\right)\right)
$$

where $\Delta y_{t}$ is the vector of GDP growth rates in Germany, the UK, France, Italy, Austria and Spain. Three vectors $\nu_{1}, \nu_{2}, \nu_{3}$ of regime-conditional mean growth rates of $\Delta y_{t}$ are distinguished.

In the model (6) we impose the rather strong restriction which requires that all countries switch regimes simultaneously. This design of the model allows the identification and analysis of the latent European cycle, while it restricts the propagation of country-specific shocks to the vector autoregression. In other words, the hidden Markov process is not informative about the propagation of business cycles across countries. Regime shifts, however, may affect some countries earlier than others due to the autoregressive dynamics in the model. The structure (6) also allows that some countries (but not all) are unaffected by shifts in regime. Given the relatively large number of countries considered and our special interest in the phenomenon of a common European cycle, modeling separate Markov processes for each country is not very appealing. In other instances, however, it may be appropriate to allow more than one state variable, such that each variable may respond to a specific state variable. This more flexible approach can be found in Phillips (1991) and Hamilton and Lin (1996). In their bivariate model of stock returns and output growth, Hamilton and Lin (1996) nest the possibility that some variables precede others in their cycle, or that different variables follow completely different Markov processes. Considering two-country two-regime models of monthly growth rates of industrial production in the US, the UK, Germany and Japan, Phillips (1991) assumes separate Markov chains for each equation. Interestingly, in none of the estimated models the null hypothesis of perfectly correlated regime shifts could be rejected which supports the presumptions made here.

The choice of a three-regime model was again based on information criteria. Using data from 1971(2) to 1995(4), a first-order VAR was unanimously preferred by AIC, HQ and SC among VAR( $p$ ) processes with $0 \leq p \leq 4$. Outliers in 1984 and 1987 have been removed by including impulse dummies (and their first lags). The Maximum Likelihood estimations are given in table 5 which also reports measures of the persistence of recession: the expected number of quarters a recession prevails (duration) and the unconditional (ergodic) probability of recessions. Whereas recessions have a duration of 6.3 quarters, the 'normal growth' state has a duration of 6.6 years. The 'catching-up' state tends to last 8.5 quarters. Major differences in the mean growth rate across regimes and a contemporaneous correlation structure in the data are evident. The hypothesis of a regime-invariant variance-covariance matrix of the Gaussian innovations $\chi^{2}(42)=128.92$ [0.0000] can be clearly rejected. We found this model to pass all misspecification tests.

The time paths of the smoothed and filtered probabilities are presented in figure 6 . The regime probabilities could be used to date the European business cycle. The classification of the regimes and the dating of the business cycle amounts to assigning an observation $y_{t}$ at time $t$ to the regime $m \in$ $\{1,2,3\}$ with the highest smoothed probability $\operatorname{Pr}\left(s_{t}=m \mid Y_{T}\right)$. In order to compare the regime 
Table 5 The MS-VAR Model of the European Business Cycle, 1970 (3) - 1995 (4).

\begin{tabular}{|c|c|c|c|c|c|c|}
\hline & Germany & UK & France & Italy & Austria & Spain \\
\hline \multicolumn{7}{|c|}{ Regime-dependent intercepts $\left(10^{-2}\right)$} \\
\hline \multirow[t]{2}{*}{$\nu_{1}$} & -0.448 & -0.033 & 0.078 & -0.261 & -0.194 & -0.086 \\
\hline & 0.149 & 0.230 & 0.166 & 0.164 & 0.141 & 0.108 \\
\hline \multirow[t]{2}{*}{$\nu_{2}$} & 0.884 & 0.463 & 0.332 & 0.436 & 0.843 & 0.117 \\
\hline & 0.162 & 0.159 & 0.100 & 0.116 & 0.152 & 0.061 \\
\hline \multirow[t]{2}{*}{$\nu_{3}$} & 0.921 & 0.109 & 0.694 & 0.991 & 1.667 & 0.351 \\
\hline & 0.252 & 0.373 & 0.137 & 0.2287 & 0.264 & 0.102 \\
\hline \multicolumn{7}{|c|}{ Autoregressive parameters at lag 1} \\
\hline \multirow[t]{2}{*}{ Germany } & -0.268 & -0.272 & 0.021 & -0.038 & -0.189 & -0.025 \\
\hline & 0.101 & 0.089 & 0.059 & 0.064 & 0.099 & 0.035 \\
\hline \multirow[t]{2}{*}{ UK } & 0.082 & 0.108 & 0.152 & 0.124 & -0.034 & 0.021 \\
\hline & 0.073 & 0.098 & 0.045 & 0.062 & 0.076 & 0.034 \\
\hline \multirow[t]{2}{*}{ France } & -0.141 & 0.017 & -0.106 & -0.054 & 0.132 & 0.040 \\
\hline & 0.157 & 0.160 & 0.094 & 0.111 & 0.175 & 0.060 \\
\hline \multirow[t]{2}{*}{ Italy } & 0.237 & 0.217 & 0.106 & 0.181 & 0.093 & -0.018 \\
\hline & 0.113 & 0.131 & 0.062 & 0.088 & 0.118 & 0.045 \\
\hline \multirow[t]{2}{*}{ Austria } & 0.101 & 0.244 & 0.067 & 0.119 & -0.456 & 0.017 \\
\hline & 0.090 & 0.095 & 0.051 & 0.064 & 0.092 & 0.034 \\
\hline \multirow[t]{2}{*}{ Spain } & -0.069 & 0.061 & 0.159 & -0.032 & 0.227 & 0.760 \\
\hline & 0.146 & 0.180 & 0.072 & 0.123 & 0.151 & 0.059 \\
\hline \multicolumn{7}{|c|}{ Dummies $\left(10^{-2}\right)$} \\
\hline \multirow[t]{2}{*}{ D87q1 } & -3.409 & 0.051 & -1.000 & -0.395 & -1.802 & 0.485 \\
\hline & 0.807 & 0.632 & 0.483 & 0.470 & 0.791 & 0.239 \\
\hline \multirow[t]{2}{*}{ D87q2 } & 1.000 & 0.033 & 0.522 & 1.250 & -0.251 & 0.290 \\
\hline & 0.896 & 0.728 & 0.525 & 0.535 & 0.875 & 0.277 \\
\hline \multirow[t]{2}{*}{ D84q2 } & -2.257 & -0.935 & -1.512 & -0.465 & -1.823 & 0.239 \\
\hline & 0.822 & 0.653 & 0.491 & 0.4844 & 0.809 & 0.246 \\
\hline \multirow[t]{3}{*}{ D84q3 } & 1.210 & -0.669 & 0.123 & -0.404 & -0.661 & 0.260 \\
\hline & 0.851 & 0.685 & 0.510 & 0.505 & 0.833 & 0.262 \\
\hline & $p_{1 i}$ & $p_{2 i}$ & $p_{3 i}$ & Duration & Erg.Prob & Obs. \\
\hline Regime 1 & 0.842 & 0.019 & 0.077 & 6.3 & 0.166 & 19.6 \\
\hline Regime 2 & 0.104 & 0.962 & 0.041 & 26.3 & 0.651 & 57.1 \\
\hline \multirow[t]{2}{*}{ Regime 3} & 0.054 & 0.019 & 0.883 & 8.5 & 0.118 & 25.3 \\
\hline & & $\ln L$ & & AIC & HQ & $\mathrm{SC}$ \\
\hline MSIH-VAR & & 2311.37 & & -42.44 & -40.91 & -38.66 \\
\hline MSI-VAR & & 2246.91 & & -42.00 & -40.90 & -39.30 \\
\hline linear VAR & & 2227.19 & & -41.96 & -41.06 & -39.73 \\
\hline
\end{tabular}

Notes: The italized numbers represent the standard errors of the estimated coefficients. MSIH-VAR is the estimated MS-VAR process with regime shifts in the (I)ntercept and regime-dependent (H)eteroskedasticity, MSIVAR is the same MS-VAR process but with an regime-invariant variancecovariance matrix $\Sigma_{1}=\Sigma_{2}=\Sigma_{3}$. The linear VAR results for the additional restriction $\nu_{1}=\nu_{2}=\nu_{3}$. 

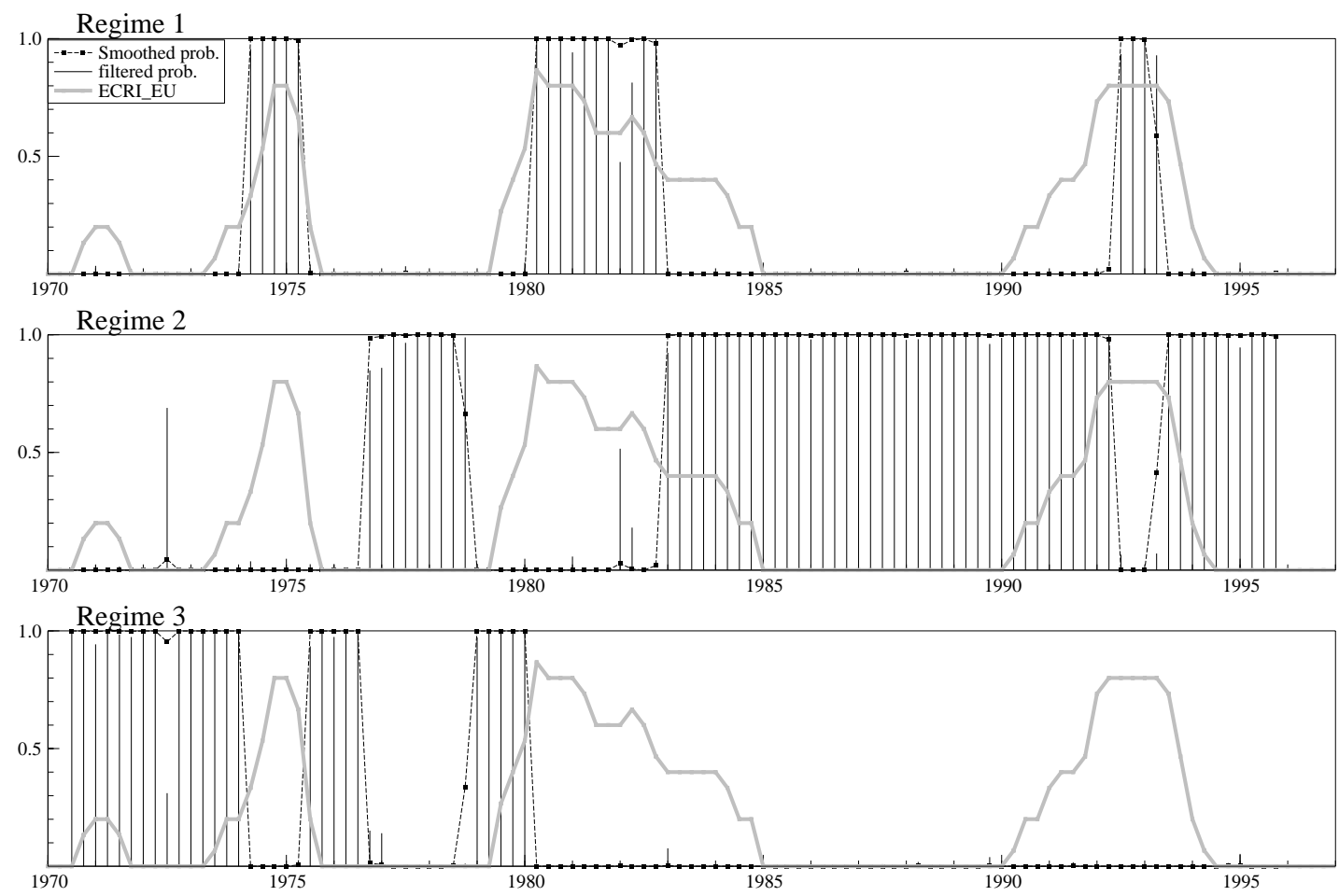

Figure 6 The European Business Cycle.

classification implied by the MS-VAR to a classical business cycle measurement, the (monthly) business cycle datings of the ECRI for Germany, UK, France, Italy and Spain have been used to construct a business cycle index for Europe which averages the observation of a recession over the five countries and the three month of a quarter. In figure 6 the index is plotted together with the smoothed and filtered probabilities of the MS-VAR. The ECRI-based index shows a similar business cycle pattern as revealed by the inferred probability of a recession, but the turning points are not distinctively pronounced. This might indicate that the business cycles in the five European countries are not all alike. To investigate this issue further, we test in the following whether some of countries are isolated against transitions of the common business cycle, i.e. their intercept does not switch with the others.

Findings of business cycle synchronism have decisive policy implications. For example, the constitution of the European Monetary Union has raised the question of a common cycle among the member countries. A lack of business cycle synchronization between the UK and other European countries could complicate the operation of monetary policy in the union and would constitute a negative indicator for joining EMU. As the presence of an European business cycle is an important indicator for the optimality of monetary union (or not), it deserve careful screening.

Table 6 reports the results of Wald specification tests regarding the significance of the regime shifts in the first moment of the system and the individual variables, respectively. Under the null hypothesis of $\nu_{1}=\nu_{2}=\nu_{3}$ etc., the unrestricted regime-dependent variances ensure the statistical identification of the model under the null hypothesis. The tests are nuisance parameter free. Therefore classical likelihood theory can be invoked, and the asymptotic null distribution of the Wald test is $\chi^{2}(r)$ where $r$ is the number of linearly independent restrictions. The regime-shifts in mean growth rates of the system are statistically highly significant. There is not only strong support for reoccurring recessions and expansions but also the presence of a third regime. A similar test can be constructed for the regime- 
Table 6 The European Business Cycle: Wald specification tests.

\begin{tabular}{ccrrrrrrr}
\hline \hline Null hypothesis & Test statistic & Germany & UK & France & Italy & Austria & Spain & \multicolumn{1}{c}{ System } \\
\hline$\nu_{1}=\nu_{2}$ & $\chi^{2}(1)$ & 37.066 & 3.301 & 1.729 & 12.945 & 25.654 & 2.712 & $\chi^{2}(6)=100.969$ \\
& & 0.0000 & 0.0692 & 0.1885 & 0.0003 & 0.0000 & 0.0996 & 0.0000 \\
$\nu_{2}=\nu_{3}$ & $\chi^{2}(1)$ & 0.027 & 1.123 & 12.041 & 7.702 & 11.488 & 9.010 & $\chi^{2}(6)=36.880$ \\
& & 0.8707 & 0.2892 & 0.0005 & 0.0055 & 0.0007 & 0.0027 & 0.0000 \\
$\nu_{1}=\nu_{2}=\nu_{3}$ & $\chi^{2}(2)$ & 38.181 & 4.422 & 14.406 & 21.056 & 43.190 & 11.548 & $\chi^{2}(12)=156.067$ \\
& & 0.0000 & 0.1096 & 0.0007 & 0.0000 & 0.0000 & 0.0031 & 0.0000 \\
\hline \hline
\end{tabular}

Note: The italized numbers represent the marginal significance level of Wald test statistic.

The regime-identifying assumption of the system test is that $\Sigma_{1} \neq \Sigma_{2} \neq \Sigma_{3}$.

dependence of the variance-covariance matrix $\Sigma$. Looking at the individual countries the picture is more diverse. In the case of recessions (regime 1) versus normal expansions (regime 2), the test hypothesis $\nu_{k 1}=\nu_{k 2}$ can very strongly rejected be for Germany, Italy, and Austria. The common recessions are less pronounced in the UK, France, and Spain whose marginal significance levels are $6.9 \%, 18.9 \%$ and $10 \%$, respectively. The hypothesis regarding the differences in the mean in the $2 \mathrm{nd}$ and the $3 \mathrm{rd}$ regime, $\nu_{2}=\nu_{3}$, can be rejected for France, Italy, Austria, and Spain with statistical error probability less $1 \%$. However, for Germany and the UK we find that their mean growth rate is not affected by transitions from the third to the second regime and vice versa. Looking at the joint test of the two hypotheses, i.e. $\nu_{1}=\nu_{2}=\nu_{3}$, regime shifts in the first moment of the series are found to be highly significant for all variables of the system (except one). Thus the notion of a common European business cycle is justified. Its weakest link is the UK which would be marginally rejected at a $10 \%$ significance level. This result seems to confirm some of the fears amongst British opponents of Britain joining the EMU. They argue that the UK cycle is essentially not synchronized with the business cycle on the continent, mainly due the dependence of British economy on the US. If this were the case, a pan-European monetary stabilization policy would not be desirable for the UK. Though, it has to be emphasized that the analysis tends to underestimate the business cycle synchronization under the conditions of a monetary union as the estimation period has been characterized by (i) monetary regimes in the UK independent and actually quite different form those in continental Europe and (ii) by strong upswings and downswings in the value of the British Sterling to the other European currencies. While the British and the European cycle have not been perfectly synchronized over the last three decades, the overall evidence for the presence of an European cycle is strong.

An important economic feature of our period of investigation has been the convergence of the European economies. Convergence could be understood in at least two different ways: as relative convergence ${ }^{2}$ and as convergence in the phase/coherence of the cycle. Convergence in cycle phase can be inferred from the statistical analysis conducted above; relative convergence is a more subtle issue. Type I convergence relates to the fact that the relative gap in output between two countries shrinks, altering the attracting equilibrium. Type II convergence refers to the situation in which the relative output gap between two countries has remained stable (the equilibrium has not changed), though there has been a shift in the mean rate of growth. It is likely that both types of convergence affected Europe over the last three decades. In the early 1970s some European countries experienced rates of growth much higher than those of their European counterparts, shifting relative output between countries and breaking down any economically meaningful cointegrating relationship (type I convergence). Type II convergence is reflected by the contemporaneity of the regime shifts in the growth process of the six European countries which constitutes the case of a common European business cycle

\footnotetext{
${ }^{2}$ This should not be confused with the concepts of $\beta$ and $\sigma$ convergence introduced by Barro and Sala-i Martin (1992).
} 

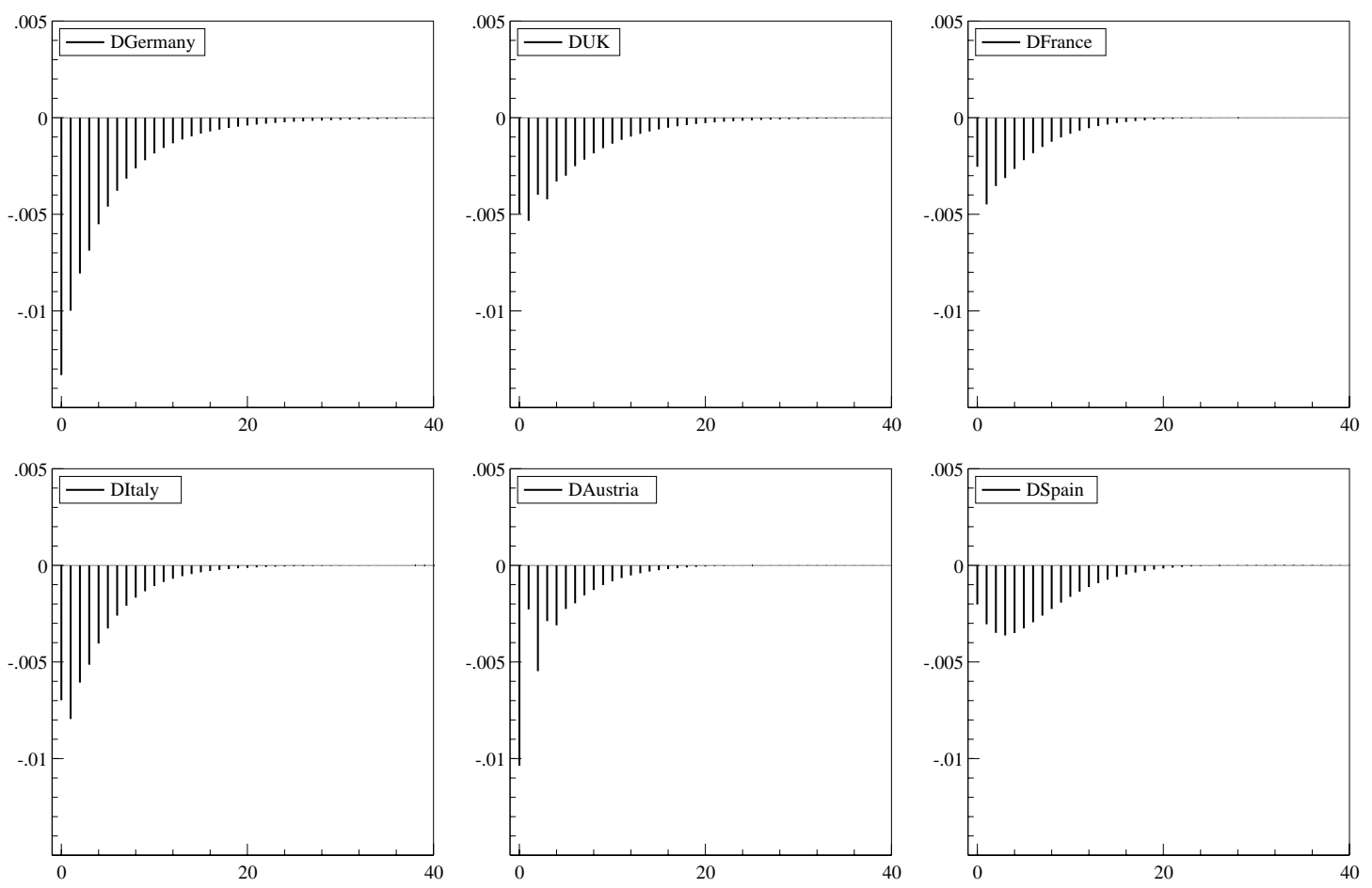

Figure 7 Effects of an European recession (transition from regime 2 to regime 1).

In the following we illustrate these stylized facts by analyzing the response of output growth in each country due to a change in regime. We focus mainly on two types of shocks, the response to a European recession (shift from regime 2 to regime 1), and the effect of the 'catching-up' regime in Europe (shift from regime 2 to regime 3). Facing an European recession (figure 7), the countries show a similar dynamic pattern. In terms of timing, all countries except Spain exhibiting the largest drop in GDP in the first or second quarter of the recession. The immediate impact is pronounced in the case of Germany and Austria which lead the downswing into a European recession. In terms of magnitude, most countries suffer a decline in output of the same size. On the other hand, the response of output growth in individual countries to a 'catching-up' regime as in the early 1970s boom presents very interesting results. Figure 8 gives the impulse responses to a shift from regime 2 to regime 3: Spain, Austria, Italy and France show strong growth, whereas the effects on the UK and Germany are slightly negative. These findings are consonant with the results from the statistical tests reported in table 6 and reflect the different tendencies in the rate of growth of the European countries under consideration in the early 1970s, foremost the catching-up of the Southern European countries.

\section{Conclusions}

In this paper we used the approach innovated by Hamilton in his analysis of the US business cycle to identify changes in the business cycle pattern in the US, Japan and a number of European economies. That approach consists in fitting a Markov-switching regime process to a vector of economic time series in question. Multi-regime Markov-switching VARs are found to be a useful tool for a comprehensive analysis.

The regime identifications in this paper distinguish between recession, normal expansion and a rapid 

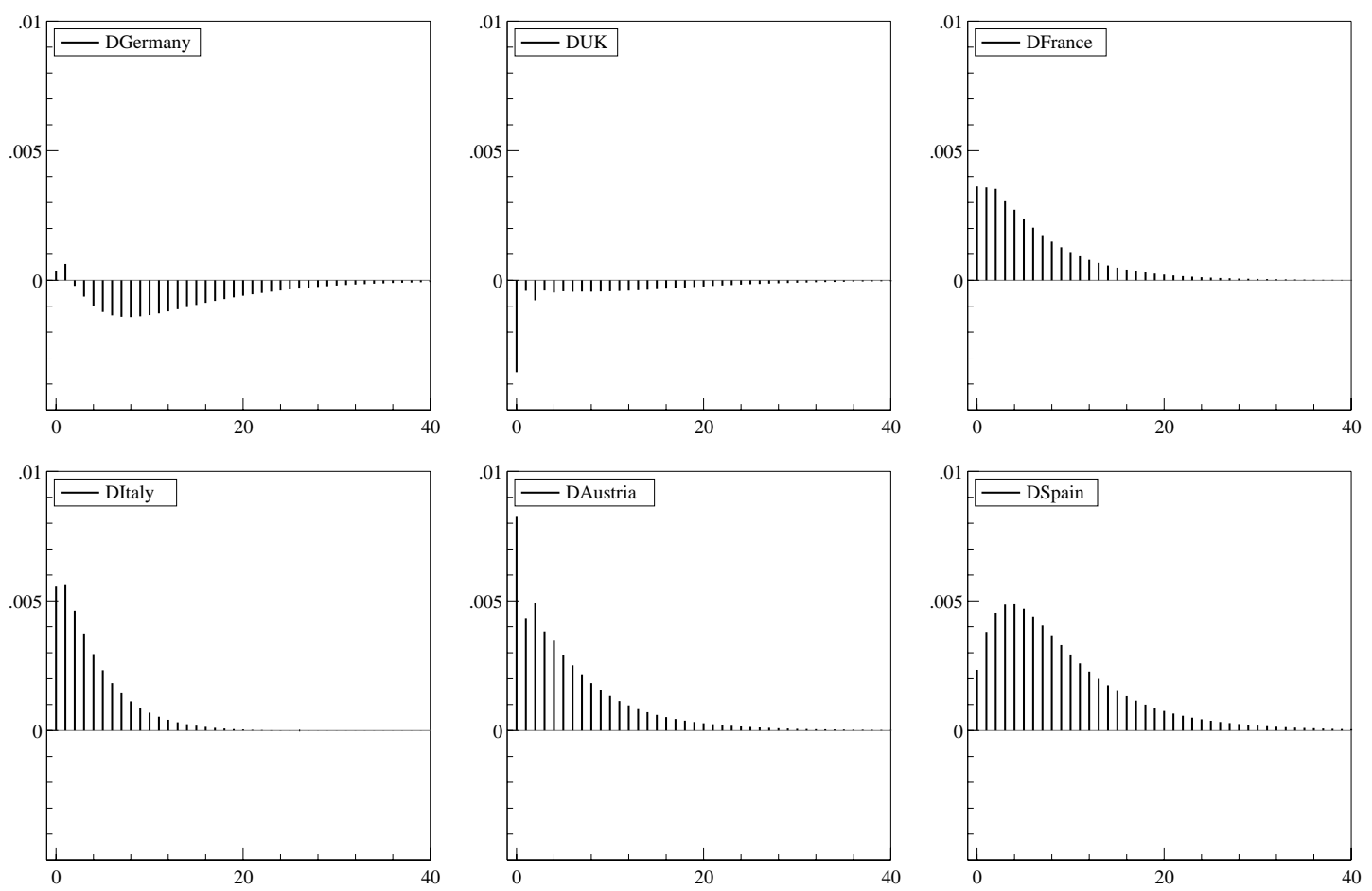

Figure 8 Effects of a transition from regime 2 to the 'catching-up' regime 3.

growth regime. The first two regimes correspond to the upturn and downturn phases of the growth cycle. Inspection of the data indicates that the last of these three regimes reflects structural change. Modeling structural change overcomes the serious problems two-regime models are faced with in detecting turning points of the business cycle. For the United States the long expansions of recent years instead of rapid, but volatile economic recovery after recessions signify basic changes in the business cycle pattern. In the case of Japan we identify long episodes of rapid economic expansions (observed until the mid 1970s) in addition to the cycle of economic expansions and relatively long economic recessions (as in the 1990s). In Europe the third regime corresponds, essentially, to the behavior of the Southern European economies at the beginning of the sample period. We find after an episode of catching-up in the 1970s, convergence in the growth pattern which suggests the notion of a European Business Cycle. The significance to be drawn from these models is that the traditional separation of the medium-run assessment of the business cycle and long-term economic growth perspective is not a promising research strategy for economies subject to structural change.

\section{References}

Artis, M., Krolzig, H.-M., and Toro, J. (1999). The European Business Cycle. CEPR Discussion Paper 2242.

Barro, R., and Sala-i Martin, X. (1992). Convergence. Journal of Political Economy, 100, 223-51.

Boldin, M. D. (1996). A check on the robustness of Hamilton's Markov switching model approach to the econometric analysis of the business cycle. Studies in Nonlinear Dynamics and Econometrics, $1,35-46$. 
Chib, S. (1998). Estimation and comparison of multiple change-point models. Journal of Econometrics, $86(2), 221-41$.

Clements, M. P., and Krolzig, H. M. (1998). A comparison of the forecast performance of Markovswitching and threshold autoregressive models of US GNP. Econometrics Journal, 1, C47-C75.

Diebold, F. X., and Rudebusch, G. D. (1996). Measuring business cycles: A modern perspective. Review of Economics and Statistics, 78, 67-77.

Filardo, A. J., and Gordon, S. F. (1994). International Co-Movements of Business Cycles: Federal Reserve Bank of Kansas, RWP94-11.

Garcia, R. (1998). Asymptotic null distribution of the likelihood ratio test in Markov switching models. International Economic Review, 39.

Hamilton, J. D. (1989). A new approach to the economic analysis of nonstationary time series and the business cycle. Econometrica, 57, 357-384.

Hamilton, J. D. (1990). Analysis of time series subject to changes in regime. Journal of Econometrics, 45, 39-70.

Hamilton, J. D., and Lin, G. (1996). Stock market volatility and the business cycle. Journal of Applied Econometrics, 11, 573-593.

Hansen, B. E. (1992). The likelihood ratio test under non-standard conditions: Testing the Markov switching model of GNP. Journal of Applied Econometrics, 7, S61-S82.

Hansen, B. E. (1996). Erratum: the likelihood ratio test under non-standard conditions: Testing the Markov switching model of GNP. Journal of Applied Econometrics, 11, 195-199.

Johansen, S. (1995). Likelihood based Inference on Cointegration in the Vector Autoregressive Model. Oxford: Oxford University Press.

Koop, G., Pesaran, M., and Potter, S. (1996). Impulse responses in nonlinear multivariate models. Journal of Econometrics, 74, 119-147.

Krolzig, H.-M. (1996). Statistical analysis of cointegrated VAR processes with Markovian regime shifts. SFB 373 Discussion Paper 25/1996, Humboldt Universität zu Berlin.

Krolzig, H.-M. (1997a). International business cycles: Regime shifts in the stochastic process of economic growth. Applied Economics Discussion Paper 194, University of Oxford.

Krolzig, H.-M. (1997b). Markov Switching Vector Autoregressions. Modelling, Statistical Inference and Application to Business Cycle Analysis. Berlin: Springer.

Krolzig, H.-M. (1998). Econometric modelling of Markov-switching vector autoregressions using MSVAR for Ox. Discussion Paper, Department of Economics, University of Oxford: http://www.economics.ox.ac.uk/hendry/krolzig.

Krolzig, H.-M., and Sensier, M. (2000). A disaggregated Markov-switching model of the business cycle in UK manufacturing. Manchester School, 68(3), 442-460.

Krolzig, H.-M., and Toro, J. (1998). A new approach to the analysis of shocks and the cycle in a model of output and employment. Working paper eco 99/30, EUI, Florence.

McConnell, M. M., and Quiros, G. P. (1998). Output fluctuations in the United States: what has changed since the early 1980s. Staff report no. 41, Federal Reserve Bank of New York.

Phillips, K. (1991). A two-country model of stochastic output with changes in regime. Journal of International Economics, 31, 121-142. 